\title{
A CLINICO-AETIOPATHOLOGICAL STUDY OF PALMOPLANTAR KERATODERMA
}

\author{
Fatima Razvi', Nayeem Sadath Haneef2, V. Sriteja ${ }^{3}$, Chudi Kavya Reddy4, Fatima Ummul Hasnath ${ }^{5}$, Ramesh Bang ${ }^{6}$
}

${ }^{1}$ Associate Professor, Department of Dermatology, Venereology and Leprosy, Deccan College of Medical Sciences, Hyderabad, Telangana.

2Professor and HOD, Department of Dermatology, Venereology and Leprosy, Deccan College of Medical Sciences, Hyderabad, Telangana.

${ }_{3}^{3}$ Postgraduate Student, Department of Dermatology, Venereology and Leprosy, Deccan College of Medical Sciences, Hyderabad, Telangana.

${ }_{4}^{4}$ Postgraduate Student, Department of Dermatology, Venereology and Leprosy, Deccan College of Medical Sciences, Hyderabad, Telangana.

5 Senior Resident, Department of Dermatology, Venereology and Leprosy, Deccan College of Medical Sciences, Hyderabad, Telangana. ${ }^{6}$ Senior Resident, Department of Dermatology, Venereology and Leprosy, Deccan College of Medical Sciences, Hyderabad, Telangana.

ABSTRACT

\section{BACKGROUND}

Palmoplantar keratodermas (PPKs) are a diverse entity of disorders that are characterised by abnormal thickening of the skin on the palms and soles. Over 50 types have been described and many of the inheritable types have been well documented in a review article by Itin and Fistarol. There is a considerable overlap and variation in clinical and histopathological feature of these conditions. Thus, a clinicopathological correlation is required for appropriate diagnosis. This would help in a better management of patients.

Aims and Objectives- To study the various aetiological factors causing palmoplantar keratoderma (PPK), to study the histopathological features of various types of palmoplantar keratoderma (PPK).

\section{MATERIALS AND METHODS}

Hundred (100) consecutive patients of palmoplantar keratoderma fulfilling the inclusion criteria, attending the outpatient Department of Dermatology, STD and leprosy, at the tertiary care centre of our medical college. After detailed history complete general, systemic and cutaneous examination was done with reference to lesions on the other parts of the body, any other dermatoses or systemic diseases. Skin biopsy was done in all the patients. Routine investigations like complete blood picture, complete urine examination, random blood sugar, serum creatinine and other tests like thyroid profile, VDRL, HIV 1 and 2 antibodies, potassium hydroxide mount of skin scrapings and PAS staining of biopsy section were done wherever necessary.

Settings and Design- An observational study.

\section{RESULTS}

Patient's age ranged from 8 to 70 years (mean age being 31). Common age group was 11 - 20 years (24.00 \%) followed by 21 - 30 years (22.00\%), 31 - 40 years (20\%), 41 - 50 years (14\%), < 10 years (8\%), 51 - 60 years $(6 \%)$ and 61 - 70 years $(6 \%)$, not seen between 71 - 80 years. Out of the total 100 patients studied, $44.00 \%$ were male and $56.00 \%$ were female patients. Male-to-female ratio was 0.78 showing female preponderance. Occurrence of PPK was seen among manual labourers (28.00\%), students (20.00\%), housewives (16.00\%) and agricultural workers (10.00\%). Involvement of palms and soles was seen in $48.0 \%$ followed by soles $28.0 \%$ and palms in $24 \%$. Clinically, 34\% patients were diagnosed by psoriasis, $26 \%$ eczema, $10 \%$ HPPK, $8 \%$ pityriasis rubra pilaris, $8 \%$ with atopic dermatitis and $2 \%$ patients with drug-induced keratoderma and $10 \%$ patients with hereditary palmoplantar keratoderma. Histopathologically, out of 34 clinically diagnosed psoriasis 24 showed typical changes, while 18 out of 26 patients showed changes of eczema. All 6 clinically diagnosed patients showed typical changes of lichen planus. All 8 clinically diagnosed patients showed typical changes of Pityriasis rubra pilaris.

\section{CONCLUSION}

The present study documented higher prevalence of palmoplantar keratoderma in the patients of age group 11 - 20 years with female preponderance. Psoriasis was more common among males and eczemas was more common in females.

\section{KEYWORDS}

Palmoplantar Keratoderma, Histopathology, Psoriasis, Eczema.

HOW TO CITE THIS ARTICLE: Razvi F, Haneef NS, Sriteja V, et al. A clinico-aetiopathological study of palmoplantar keratoderma. J. Evolution Med. Dent. Sci. 2018;7(13):1620-1624, DOI: 10.14260/jemds/2018/367

'Financial or Other Competing Interest': None.

Submission 08-02-2018, Peer Review 09-03-2018,

Acceptance 16-03-2018, Published 26-03-2018.

Corresponding Author:

Dr. Nayeem Sadath Haneef,

3/102, Kalyani, Sahra States,

Mansoorabad, LB Nagar,

Hyderabad-500068, Telangana.

E-mail:dr_nayeemsadath@yahoo.co.in

DOI: $10.14260 /$ jemds $/ 2018 / 367$

\section{(c) $(1) \risingdotseq$}

\section{BACKGROUND}

Palmoplantar keratodermas (PPKs) are a diverse entity of disorders that are characterised by abnormal thickening of the skin on the palms and soles. Traditionally, they have been classified as either hereditary or acquired and are distinguished from each other on the basis of mode of inheritance, presence of transgrediens (defined as contiguous extension of hyperkeratosis beyond the palmar and/or plantar skin), co-morbidities with other symptoms and extent of epidermal involvement namely diffuse, focal and punctate. 1,2 
- Diffuse keratodermas affect most of the palms and soles.

- Focal keratodermas mainly affect pressure areas.

- Punctate-type keratodermas result in tiny bumps on the palms and soles.

- Most often the abnormal skin involves only the palms and soles (non-transgradient), but sometimes it extends onto the top of the hands and feet as well (transgradient).

In some rare forms of keratoderma, other organs in the body may be affected in addition to the skin and the keratoderma can be a marker of this internal abnormality.

The table below lists the main types of hereditary palmoplantar keratoderma (PPK).

Diffuse hereditary palmoplantar keratodermas,

- Unna-Thost type (autosomal dominant)

- Vorner's type (autosomal dominant)

- Mal de Meleda type (autosomal dominant or recessive)

- Huriez syndrome (autosomal dominant)

- Olmsted syndrome (unknown inheritance pattern)

- Vohwinkel syndrome (autosomal dominant)

- PPK with sensorineural deafness (mitochondrial inheritance)

- Bart-Pumphrey syndrome (autosomal dominant)

- Hidrotic ectodermal dysplasia (autosomal dominant)

- Papillon-Lefevre syndrome (autosomal recessive)

- Diffuse PPK with woolly hair and arrhythmogenic cardiomyopathy (autosomal recessive)

- Focal hereditary palmoplantar keratodermas

- PPK striata/ areata type (autosomal dominant)

- Hereditary painful callosities (autosomal dominant)

- Howel-Evans syndrome or tylosis (autosomal dominant)

- Richner-Hanhart syndrome (autosomal recessive)

- Pachyonychia congenita (autosomal dominant)

- $\quad$ Striate PPK with woolly hair and dilated cardiomyopathy (autosomal recessive)

- Punctate palmoplantar keratodermas

- Punctate keratoderma (autosomal dominant)

- Filiform keratoderma (autosomal dominant)

- Marginal keratoderma (autosomal dominant)

Acquired palmoplantar keratodermas may be focal or diffuse. They may arise in association with a variety of different skin and internal conditions:

- An inflammatory skin condition (eg, eczema or psoriasis)

- Infections

- Medications and toxins

- An internal malignancy

- A non-cancerous internal disease

- Circulation problems

Over 50 types have been described and many of the inheritable types have been well documented in a review article by Itin and Fistarol. ${ }^{3}$

Typical lesions of hyperkeratosis of palms and soles do not create any problem, but when slight variation is there it becomes difficult to diagnose and that changes the line of treatment. In view of the multiple aetiologies involved in this interesting group of diseases and also a wide felt paucity of clinical and epidemiological studies on this subject, this study has been undertaken with an objective of finding out the incidence of various aetiological factors causing PPK.

There is a considerable overlap and variation in clinical and histopathological feature of these conditions. Thus, a clinicopathological correlation is required for appropriate diagnosis. This would help in a better management of patients.

\section{Objective}

To study the various aetiological factors causing palmoplantar keratoderma (PPK), to study the histopathological features of various types of palmoplantar keratoderma (PPK).

\section{MATERIALS AND METHODS \\ Study Design}

An observational study.

\section{Setting}

Dermatology, Venereology and Leprosy Department of a Tertiary Care Hospital attached to a Postgraduate Training Institute in Telangana State of India.

\section{Patients and Period}

Hundred consecutive patients of palmoplantar keratoderma fulfilling the inclusion criteria from October 2013 to May 2015 ( 2 years) were included.

\section{Inclusion Criteria}

All the patients presenting with hereditary and acquired palmoplantar keratoderma of all ages and both the sexes were included.

\section{Exclusion Criteria}

Patients already on prior treatment for the condition were excluded, as histopathological features may be altered due to treatment.

\section{Evaluation Protocol}

A complete history with a stress on the age of onset/ duration of symptoms, exacerbations and remissions, family history of similar disease and history of any other previous or concomitant illnesses was recorded. Complete general, systemic and cutaneous examination was done with reference to lesions on the other parts of the body, any other dermatoses or systemic diseases. Skin biopsy was done in all the patients.

Routine investigations like complete blood picture, complete urine examination, random blood sugar, serum creatinine and other tests like thyroid profile, VDRL, HIV 1 and 2 antibodies, potassium hydroxide mount of skin scrapings and PAS staining of biopsy section were done wherever necessary.

\section{RESULTS}

\section{Age Distribution (Table 1, Figure 1)}

Age of the patients ranged from 8 to 70 years (mean age being 31). Most number of patients belonged to age group of 
11 - 20 years $(24.00 \%)$ followed by the age group of $21-30$ years $(22.00 \%), 31-40$ years $(20 \%), 41-50$ years $(14 \%)$, $<10$ years (8\%), $51-60$ years $(6 \%)$ and $61-70$ years $(6 \%)$. No patients were seen in the age group of 71 - 80 years.

In present study, histopathologically diagnosed psoriasis was most common among 21 - 30 years of age (35.2\%), eczema was common among 11 - 20 years of age $(37.5 \%)$, HPPK was common among 11 - 20 years of age (60\%), lichen planus was common among 31 - 40 years of age (66.6\%), two cases of drug-induced PPK was seen on antiepileptic and atopic dermatitis was common among $<10$ years of age $(66.6 \%)$.

\begin{tabular}{|c|c|c|}
\hline Age Group & Number of Patients, n= 100 & Percentage \\
\hline$<10$ years & 8 & $8 \%$ \\
\hline $11-20$ years & 24 & $24 \%$ \\
\hline $21-30$ years & 22 & $22 \%$ \\
\hline $31-40$ years & 20 & $20 \%$ \\
\hline $41-50$ years & 14 & $14 \%$ \\
\hline $51-60$ years & 6 & $6 \%$ \\
\hline$>60$ years & 6 & $6 \%$ \\
\hline Total $\mathbf{n = 1 0 0}$ & $\mathbf{1 0 0}$ & $\mathbf{1 0 0} \%$ \\
\hline \multicolumn{2}{|c|}{ Table 1. Age distribution of PPK } \\
\hline \multicolumn{2}{|c}{}
\end{tabular}

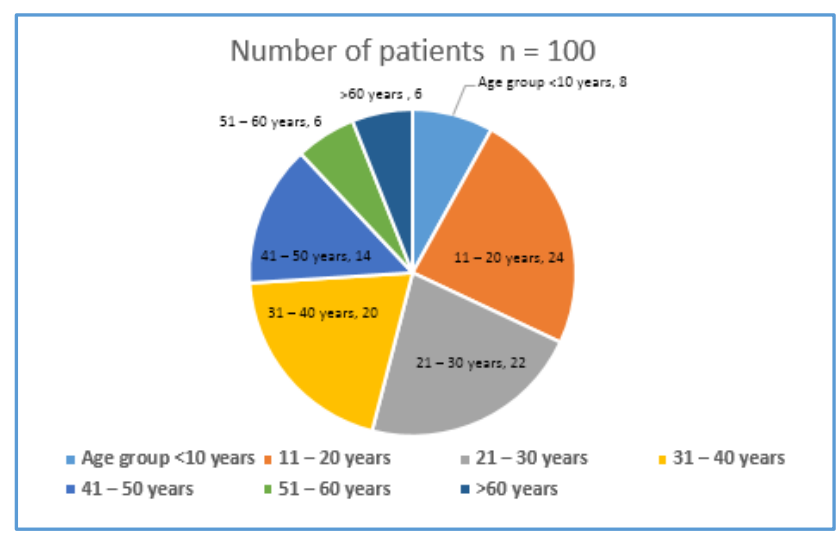

Figure 1

\section{Sex Distribution}

Out of the total 100 patients studied, $44.00 \%$ were male and $56.00 \%$ were female patients. Male-to-female ratio was 0.78 showing female preponderance. In our study, histopathologically confirmed diagnosis of psoriasis patients, $18(52.94 \%)$ were male and $16(47.05 \%)$ were female. In patients with eczema, $12(37.5 \%)$ were males and $20(62.5 \%)$ were females. In patients with HPPK, 3 (37.5\%) were males and $5(52.5 \%)$ were females out of 8 .

\section{Occupation (Table 2, Figure 2)}

Occurrence of PPK was mostly seen among manual labourers (28.00\%), students (20.00\%), housewives (16.00\%) and agricultural workers $(10.00 \%)$. In our study among manual labourers eczema (50\%) was most common followed by psoriasis (42.85\%), among students atopic dermatitis (30\%) and HPPK $(30 \%)$ was more common followed by psoriasis (20\%), among housewives psoriasis $(37.5 \%)$ was most common followed by eczema (25\%) and among agricultural workers eczema (60\%) was commonly followed by psoriasis (40\%).

\begin{tabular}{|c|c|c|}
\hline Occupation & Number & Percent \\
\hline Manual labourer & 28 & $28 \%$ \\
\hline Student & 20 & $20 \%$ \\
\hline Housewife & 16 & $16 \%$ \\
\hline Agriculture & 10 & $10 \%$ \\
\hline Unemployed & 8 & $8 \%$ \\
\hline Software Engineer & 6 & $6 \%$ \\
\hline Teacher & 6 & $6 \%$ \\
\hline Tailor & 6 & $6 \%$ \\
\hline Total (n= 100) & $\mathbf{1 0 0}$ & $\mathbf{1 0 0} \%$ \\
\hline Table 2. Occupation Wise distribution of PPK \\
\hline
\end{tabular}

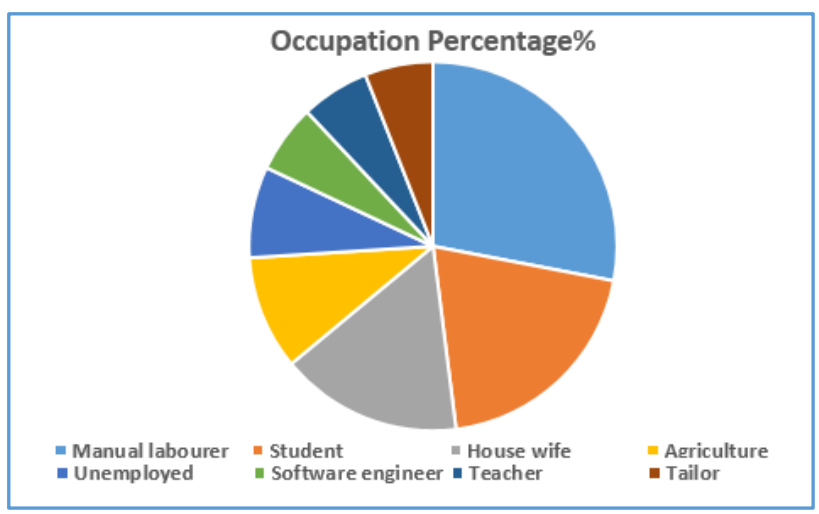

Figure 2

\section{Distribution by Site}

Involvement of both palms and soles was seen in $48.0 \%$ followed by only soles in $28.0 \%$ and on only palms in $24 \%$.

\section{Disease Distribution (Table 3, Figure 7)}

Clinical Diagnosis- In our study clinically $34 \%$ of cases were diagnosed to be psoriasis (Figure 3 and 4), 26\% of cases as eczema, $10 \%$ of cases as hereditary palmoplantar keratoderma, $8 \%$ of cases as pityriasis rubra pilaris and with atopic dermatitis, $6 \%$ of cases as lichen planus and with tinea manuum, $2 \%$ of cases as drug-induced palmoplantar keratoderma.

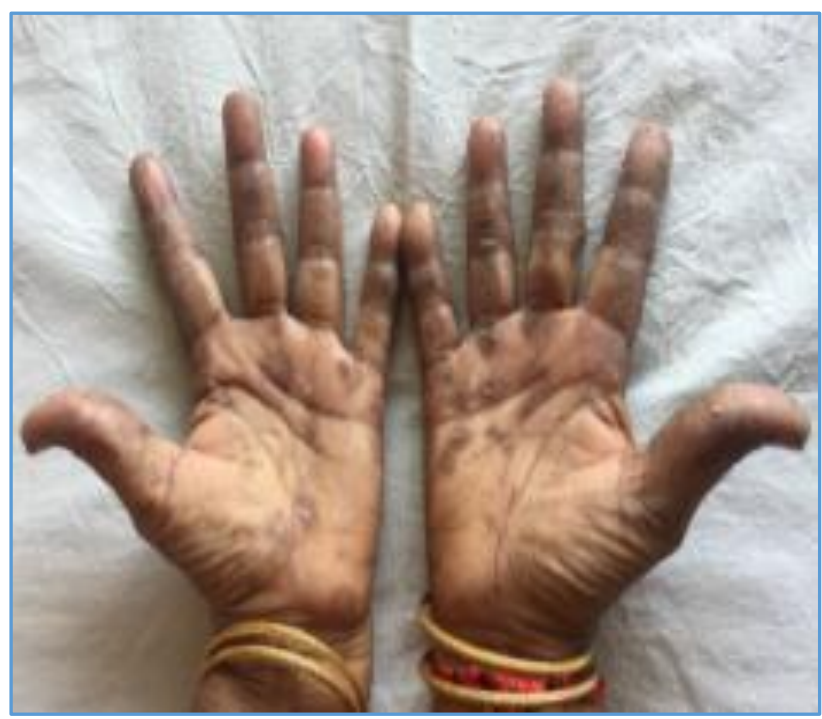

Figure 3. Palmar Psoriasis 


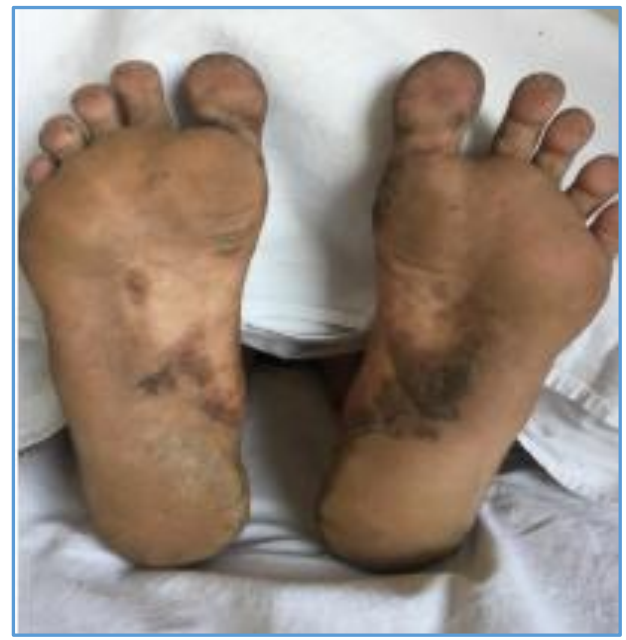

Figure 4. Plantar Psoriasis

\section{Histopathological Diagnosis}

In our study histopathologically $34 \%$ of cases were psoriasis (Figure 5), 32\% were diagnosed as eczema, 8\% with hereditary palmoplantar keratoderma, $8 \%$ with pityriasis rubra pilaris, $8 \%$ with atopic dermatitis, $6 \%$ with lichen planus (Figure 6), 2\% with tinea manuum and $2 \%$ with druginduced palmoplantar keratoderma.

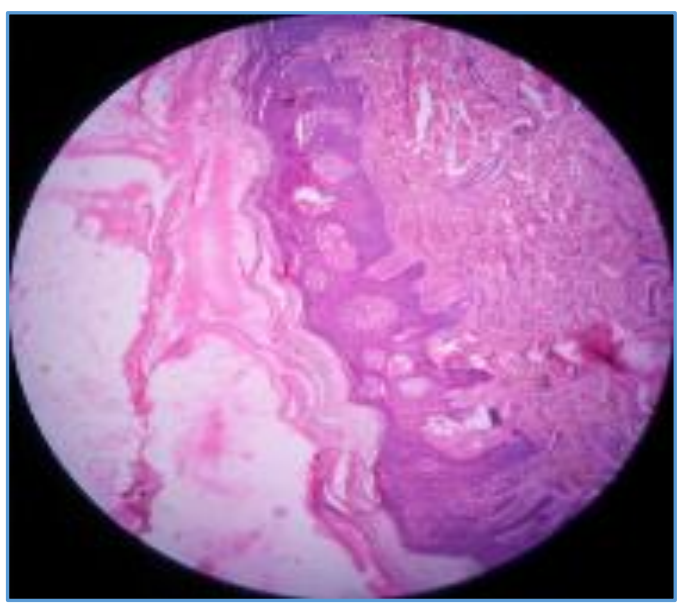

Figure 5

Figure 5. Histopathology of palmoplantar psoriasis: hyperkeratosis, parakeratosis, clubbing of rete ridges, suprapapillary thinning.

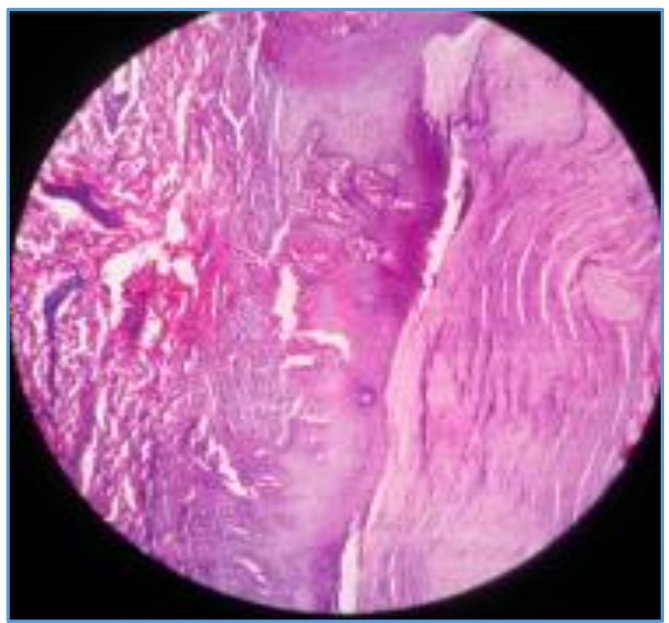

Figure 6
Figure 6. Histopathology of lichen planus: hyperkeratosis, orthokeratosis, parakeratosis, irregular acanthosis, wedgeshaped hypergranulosis, saw-toothed rete-ridges.

\begin{tabular}{|c|c|c|}
\hline $\begin{array}{c}\text { Condition } \\
(\mathrm{n}=100)\end{array}$ & \begin{tabular}{|c|} 
Clinical \\
Diagnosis (\%) \\
\end{tabular} & $\begin{array}{c}\text { Histopathological } \\
\text { Diagnosis (\%) }\end{array}$ \\
\hline Psoriasis & $34(34 \%)$ & $34(\%)$ \\
\hline Eczema & $26(26 \%)$ & $32(\%)$ \\
\hline HPPK & $10(10 \%)$ & $8(\%)$ \\
\hline A.D & $8(8 \%)$ & $8(\%)$ \\
\hline P.R.P & $8(8 \%)$ & $8(\%)$ \\
\hline L.P & $6(6 \%)$ & $6(\%)$ \\
\hline T.M & $6(6 \%)$ & $2(\%)$ \\
\hline DPPK & $2(2 \%)$ & $2(\%)$ \\
\hline
\end{tabular}

Table 3. Clinical Diagnosis and Histopathology of PPK

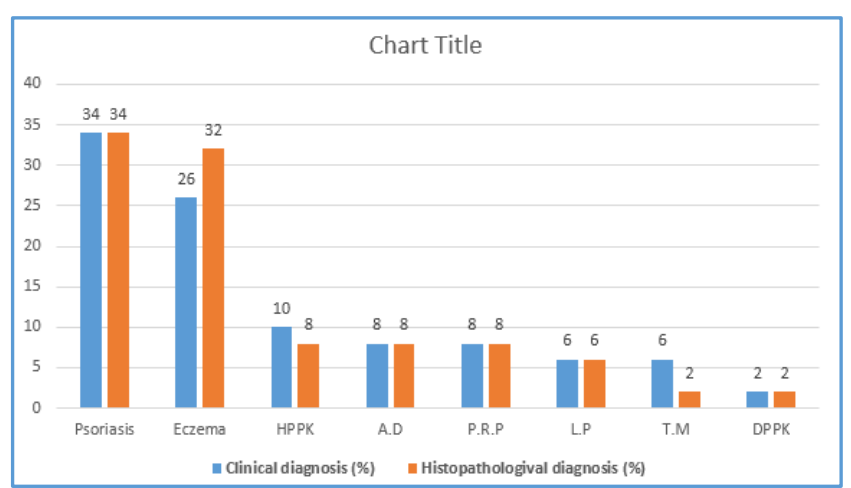

Figure 7

\section{Site and Disease Distribution}

In our study both palms and soles were involved in $76.4 \%$ of psoriasis patients, $37.5 \%$ of eczema patients, all patients of HPPK. Soles only were involved in $17.6 \%$ of psoriasis patients, $18.75 \%$ of eczema patients and all patients with atopic dermatitis. Palms only were involved in 5.8\% of psoriasis patients and $43.75 \%$ of eczema patients.

\section{DISCUSSION}

Palmoplantar keratodermas (PPKs) refer to a thickening of the skin of the palms and soles caused by excessive keratin. ${ }^{1}$ They are a heterogeneous group of disorders that are classically grouped as either hereditary or acquired.

The hereditary palmoplantar keratodermas are caused by a gene abnormality that results in abnormal skin protein (keratin). They can be inherited in an autosomal dominant or autosomal recessive.

Acquired palmoplantar keratodermas may arise as a result of infection, internal disease or cancer, inflammatory skin conditions or medications. ${ }^{4}$

These conditions do not always present with typical manifestations such as classical skin lesions and nail changes, and therefore known clinical features about these diseases might not be helpful in accurate diagnosis on all occasions. This fact is substantiated by many studies such as Matsunaga J et al (1998) who stated that the morphology of hand psoriasis is often typical, but sometimes it has eczematous features posing diagnostic problems. ${ }^{5}$

In a study of 154 cases by Khandpur et al (2011), hyperkeratotic eczema has been found challenging to distinguish and may overlap with psoriasis, although it usually does not have the degree of erythema or the welldemarcated nature of psoriasis. Such dilemma is likely to 
have a major impact on the therapeutic approach and consequently on the prognosis. ${ }^{6}$

Hence, a clinicopathological correlation is required for appropriate diagnosis. This would help in a better management of patients. ${ }^{6}$

The primary distinguishing factors that stratify hereditary and acquired groups of PPKs are age of onset, positive family history and associated features. Hereditary PPKs tend to occur earlier, can be traced in family pedigrees and may be associated with well described syndromes. Conversely, acquired PPKs occur later in life without a positive family history and tend to be attributable to an underlying aetiology..$^{7-10}$

In the present study where 100 clinically diagnosed patients of palmoplantar keratoderma were evaluated for age, sex, occupation, distribution and clinicopathological correlation, it was found that the commonest age group of palmoplantar keratoderma involved was 11 - 20 years, which was similar to Mahajan et al study, but at variance with Sandeep et al study in which the commonest age group was 41 - 50 years.

It was also found that the commonest age group of psoriasis involved was 21 - 30 years, which was similar to Chopra et al study, but at variance with Agarwal et al study in which the commonest age group was 31 - 40 years. In a study of Chopra et al, average age group in hyperkeratotic eczema was 42.30 years. Hersle and Mobacken found the mean age for hyperkeratotic eczema as 46 years. 11,12

Eczema was seen more in females of younger age group at a younger age group (11 - 20 years) in the present study, which could probably be attributed to the socioeconomic status to which the patients belong, subjecting them to increased exposure to detergents, vegetable juices and various household dust.

In the present study male-to-female ratio was found to be 0.72: 1 , which is at variance with Verma et al study that showed it to be $4: 1$.

In the present study male-to-female ratio among patients of psoriasis was found to be 1.12: 1 , which is at variance with Mahajan et al study that showed 3.6: 1 and Chopra et al study that showed 1.28: 1 .

In the present study male-to-female ratio among patients of eczema was found to be $0.6: 1$, which is the same as that of Mahajan et al and is at variance with Agarwal et al study that showed 2.2: 1 .

In our present study palmoplantar keratoderma was mostly seen among manual labourers (28\%), housewives $(16 \%)$, students $(20 \%)$ and agricultural workers $(10 \%)$. But according to Sandeep study palmoplantar keratoderma was mostly seen among agricultural workers (53\%), housewives (20\%), manual labourers (8\%) and students (8\%), (Table 4).

\begin{tabular}{|c|c|c|c|c|}
\hline Study & $\begin{array}{c}\text { Manual } \\
\text { Labourers }\end{array}$ & Housewives & $\begin{array}{c}\text { Agricultural } \\
\text { Workers }\end{array}$ & Student \\
\hline Sandeep & $8 \%$ & $20 \%$ & $53 \%$ & $8 \%$ \\
\hline $\begin{array}{c}\text { Present } \\
\text { Study }\end{array}$ & $28 \%$ & $16 \%$ & $10 \%$ & $20 \%$ \\
\hline \multicolumn{5}{|c|}{ Table 4. Comparison of Occupation Wise distribution } \\
of PPK with Various Studies \\
\hline
\end{tabular}

In our present study, involvement of both palms and soles was seen in $48.0 \%$ followed by only soles in $28.0 \%$ and on only palms in $24 \%$. According to Sandeep's study, involvement of both palms and soles was seen in $60 \%$ followed by only soles in $25 \%$ and on only palms in $15 \%$, (Table 5).

\begin{tabular}{|c|c|c|c|}
\hline Study & Palms & Soles & Palms + Soles \\
\hline Sandeep Study & $15 \%$ & $25 \%$ & $60 \%$ \\
\hline Present Study & $24 \%$ & $28 \%$ & $48 \%$ \\
\hline \multicolumn{3}{|c|}{$\begin{array}{r}\text { Table 5. Comparison of Site distribution } \\
\text { of PPK with Various Studies }\end{array}$} \\
\hline
\end{tabular}

Seasonal Influence- Exacerbation of palmoplantar keratoderma in both winter and summer seasons was seen in the present study.

\section{CONCLUSION}

The present study documented higher prevalence of palmoplantar keratoderma in the patients of age group 11-20 years with female preponderance. Psoriasis was more common among males and eczema was more common in females. Psoriasis was the leading cause in this study followed by eczema. There is a considerable overlap and variation in clinical and histopathological features of these conditions. Thus, a clinicopathological correlation is required for appropriate diagnosis that would help for a better management of patients.

\section{REFERENCES}

[1] Greither A. Erbliche palmoplantarkeratosen. Hautarzt 1977;28:395-403.

[2] Salamon T. An attempt at classification of inherited disorders of keratinization localized mainly, not exclusively on the palms and soles. Dermatol Monatsschr 1986;172(10):601-5.

[3] Itin PH, Lautenschlager S. Palmoplantar keratoderma and associated syndromes. Semin Dermatol 1995;14(2):152-61.

[4] Judge MR, McLean WHI, Munro CS. Disorders of keratinization. In: Burns T, Breathnac S, Cox N, et al. Rook's textbook of dermatology. $7^{\text {th }}$ edn. Blackwell Publishing Company, 2004:p.34.1-111.

[5] Matsunaga J, Maibach HI, Epstein E. Scalp and hair, palms and soles. In: Roenigk HH, Maibach HI, (eds). $3^{\text {rd }}$ edn. New York: Marcel Dekker, 1998:45-57.

[6] Agarwal P, Nijhawan M, Mathur D. Clinicopathological study of hyperkeratotic lesions of palms and soles: an observational study. International Journal of Scientific Study 2014;1(5):19-23.

[7] Berger TG, Odom RB, James WD. Andrews' diseases of the skin: clinical dermatology. 9th edn. Philadelphia (PA): WB Saunders, 1990:245-50.

[8] Goldsmith LA, Katz SI, Gilchrest BA, et al. Fitzpatrick's dermatology in general medicine. $8^{\text {th }}$ edn. New York: McGraw-Hill, 2003:538-49.

[9] Champion RH, Burton JL, Burns DA, et al. Rook, Wilkinson, Ebling textbook of dermatology. $7^{\text {th }}$ edn. Malden (MA): Blackwell Science Ltd, 2004;34:79-107.

[10] Bolognia JL, Jorizzo JL, Rapini RP. Dermatology. New York: Mosby, 2003:809-10.

[11] Chopra A, Maninder, Gill SS. Hyperkeratosis of palms and soles: clinical study. Indian J Dermatol Venereol Leprol 1997;63(2):85-8.

[12] Hersle K, Mobacken H. Hyperkeratotic dermatitis of the palms. Br J Dermatol 1982;107(2):195-201. 